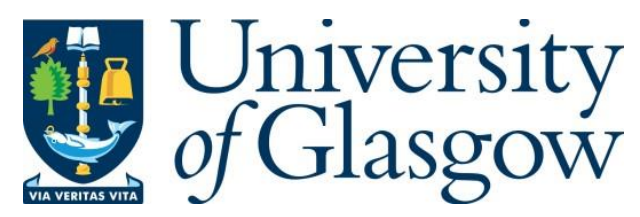

Krawczyk, M., Bartczak, A., Hanley, N. and Stenger, A. (2016) Buying spatiallycoordinated ecosystem services: an experiment on the role of auction format and communication. Ecological Economics, 124, pp. 36-48.

There may be differences between this version and the published version. You are advised to consult the publisher's version if you wish to cite from it.

http://eprints.gla.ac.uk/154104/

Deposited on: 20 December 2017

Enlighten - Research publications by members of the University of Glasgow http://eprints.gla.ac.uk 


\title{
Buying spatially-coordinated ecosystem services: An experiment on the role of auction
}

\section{format and communication.}

\author{
Michal Krawczyk ${ }^{\mathrm{a}}$, Anna Bartczak ${ }^{\mathrm{a}}$, Nick Hanley ${ }^{\mathrm{b}}$, and Anne Stenger ${ }^{\mathrm{c}}$ \\ ${ }^{a}$ Faculty of Economic Sciences, Warsaw Ecological Economics Center, University of \\ Warsaw, ul. Dluga 44/50, 00-241 Warsaw, Poland \\ ${ }^{\mathrm{b}}$ Department of Geography and Sustainable Development, University of St Andrews, UK \\ ${ }^{c}$ INRA, Laboratoire d'Économie Forestière - Centre de Nancy, 14 rue Girardet, 54042 \\ Nancy, France and BETA, UMR 7522 Université de Strasbourg, France
}

\begin{abstract}
Procurement auctions are one of several policy tools available to incentivise the provision of ecosystem services and biodiversity conservation. Successful biodiversity conservation often requires a landscape-scale approach and the spatial coordination of participation, for example in the creation of wildlife corridors. In this paper, we use a laboratory experiment to explore two features of procurement auctions in a forest landscape: the pricing mechanism (uniform vs. discriminatory) and availability of communication (chat) between potential sellers. We modify the experimental design developed by Reeson et al. (2011) by introducing uncertainty (and hence heterogeneity) in the production value of forest sites as well as an automated, endogenous stopping rule. We find that discriminatory pricing yields to greater environmental benefits per government dollar spent, chiefly because it is easier to construct long corridors. Chat also facilitates such coordination but also seems to encourage collusion in sustaining high prices for the most environmentally attractive plots. These two effects offset each other, making chat neutral from the viewpoint of maximizing environmental effect per dollar spent.
\end{abstract}

JEL classifications: C92; D44; Q23; Q57; Q58

Keywords: Conservation auctions; Spatial coordination; Chat in experiments; Discriminatory and uniform auctions; Biodiversity conservation; Provision of ecosystem services 


\section{Introduction}

Procurement or reverse auctions are one of several Payment for Ecosystem Service (PES) design options available to incentivise the provision of ecosystem services and biodiversity conservation on privately-owned land (Hanley et al., 2012). In this setting, they are often referred to as "conservation auctions". Such auctions offer the potential to deliver a cost-efficient allocation of limited government funds for conservation (Latacz-Lohmann and van der Hamsvoort, 1997; Schilizzi and Latacz-Lohmann, 2007) and to reduce information asymmetries concerning private owners' costs of supplying an ecosystem service or of conserving biodiversity (Ferraro, 2008, Reeson et al., 2011; Reeson and Whitten, 2014). They involve multiple potential sellers, each typically endowed with multiple units of a "good" for sale - here, plots of land offered to be managed in a specific way - and a single bidder interested in purchasing multiple units. Conservation auctions have attracted limited attention in the theoretical literature so far, but have been extensively studied using lab experiments and simulation modelling (Hailu and Thoyer, 2010).

However, little research has been conducted to date on the ability of conservation auctions to deliver environmental improvements in a spatially-coordinated manner. This is important since the ecological benefits delivered by PES schemes often depend on the spatial configuration of enrolled sites. For example, if the goal of such a scheme is to improve water quality in catchments subject to diffuse pollution from agriculture, then the location of farms who are awarded contacts is crucial to determining the change in water quality resulting from the scheme. An interesting specific case is that of spatial agglomeration, where awarding 
contacts to adjoining parcels of land (adjoining farms) is more effective in attaining conservation outcomes than a random spatial pattern of sign-ups (Parkhurst and Shogren, 2007; Banerjee et al, 2012, 2014a). Such spatial coordination can be beneficial if a species requires access to several habitat types, if wildlife corridors are being created, or if a minimum viable area of land contiguously enrolled in the scheme is necessary to allow a species to thrive. In such cases, spatial agglomeration delivers higher environmental benefits for a given total area of hectares enrolled.

One study where authors have looked at the potential of conservation auctions to achieve desired spatial patterns of sign-ups in a landscape is Windle et al. (2009). The authors investigate the use of auctions to encourage the creation of landscape corridors in Queensland, Australia. They found that the auction mechanism succeeded in producing connected corridors of enrolled land, with $70 \%$ of successful bidders being spatially connected. Banerjee et al. (2014b) also use an experimental approach to investigate spatial coordination in auctions. Participants in their experiment are informed of a spatial rule which was used to allocate a score to bids in conjunction with the amount offered. The authors included a treatment whereby the treated group of participants were told about the targeted spatial outcome of the auction. They find that the treatment had an effect on rent-seeking but no impact on auction efficiency. In the key reference paper for our study, Reeson et al (2011) investigate the effects of promoting connectivity between sites in a de-contextualized setting. In their lab experiment, they considered a homogeneous landscape of 400 plots divided among 10 owners/bidders, and investigate the effects of having multiple rounds of the auction with different stopping rules for 
when the process ended. Other authors such as Bamiere et al (2013) and Iftekhar and Tisdell (2015) use simulation, rather than lab experiments, to investigate spatial coordination in PES design.

The main objectives of the present paper are to explore the impacts of auction format (Discriminatory Price vs. Uniform Price) and the opportunity for communication between participants on environmental benefit maximization and the efficiency of providing ecosystem services by forest owners. We do this in the context where the spatial location of successful bidders matters for the delivery of overall environmental benefit and where there is variation in the supply price of conservation across landowners.

We build upon the experimental design developed by Reeson et al. (2011), introducing four principal modifications which seem potentially important in improving cost-effective spatial coordination in conservation auctions. First, we account for heterogeneity in the production value of plots, both between and within land owners. The rationale behind this is that forests differ in terms of tree species, age and planting density, and thus deliver different production values. The opportunity costs of conservation can thus vary considerably over space. Second, we use an automated, endogenous stopping rule in a multiple-round auction, which means participants do not know which round of bidding will be the last. If subjects do know which round is going to be the last, they have limited incentives to bid in an economically-rational manner in all previous rounds, and can signal their collusive intentions in a costless manner through cheap talk (Cason et al., 2003). 
Third, we analyse two different auction formats: Discriminatory Pricing and Uniform Pricing. Both of them have their merits in practical applications, and these merits have been compared in many previous experiments (Cason and Gangadharan, 2005). In Discriminatory Price auctions, transaction prices are determined in a straightforward manner-they are identical to accepted offers - and this simplicity is a major virtue in these otherwise complicated markets. However, they create incentives for landowners to bid higher than their true minimum willingness to accept. Uniform Price auctions place less burden on the participants as far as the determination of their bidding strategy is concerned, since the bidder can focus on their minimum acceptable price level. Participants may consider the uniform price format as being fairer (Kahneman et al. 1986; Cong et al, 2010). In familiar single-object auctions, the analogue of the Discriminatory Price auction is the first-price sealed-bid auction, while the second-price (Vickrey, 1961) auction is the analogue of the Uniform Price auction. The properties of these two variants are well understood. It is tempting to extend this reasoning to multiple-object auctions (in which buyers submit a number of bids for the first, second, $\cdots$ and $n$-th units - that is, a demand schedule), but this is an oversimplification. In the case of multiple bids, any buyer's lower bid can affect the price paid to a (successful) higher bid so that some shading pays off. This holds for the case of multiple potential sellers and a single buyer. If sellers are only interested in selling one unit, then under the uniform rule they should bid their reservation price. However, it pays to add some mark-up on all but the first unit if they submit an entire demand scheme. 
In our case of a Uniform price auction with a spatial aspect, finding a theoretical prediction for the relative performance of the two formats is difficult. Nevertheless, by analogy with the situations sketched above, we generally expect offers in the Discriminatory Price treatment to be higher than reservation prices in the Uniform Price treatment. It also seems natural that horizontal corridors of adjacent plots purchased will be more common under Discriminatory Pricing. This is because in such a corridor there will typically contain at least one highly-productive plot. To contract for this highly-productive plot under a Uniform price format would mean that the buyer has to pay a very high price for all other connected plots too, which will not be cost-effective.

The last of our modifications examines the effect of communication between subjects in the course of the auction. From a practical viewpoint, this is an important consideration because the owners of different forests or farms will typically know each other and might indeed want to coordinate their strategies. Moreover, multi-round auctions will often give participants multiple opportunities to communicate. On one hand, we expect communication to facilitate collusion, thereby decreasing the auction's cost-effectiveness. One the other hand, since environmental benefits depend on participants' abilities to coordinate strategies with their neighbors such that larger contiguous areas of wildlife protection are created, communication may improve an auction environmental performance (Balliet,2010, Vogt et al., 2013). The overall effect is thus hard to predict.

In what follows, the remainder of the paper is organized as follows. Section 2 contains the experimental design, treatments, information provided to subjects and the applied procedures. 
Section 3 describes and discusses the obtained results, followed by Conclusions which are presented in Section 4.

\section{Methods}

The experiment is framed in the context of forest biodiversity protection. Specifically, we consider a national park (NP) surrounded by hitherto un-protected privately-owned land. Such a situation is quite typical in the European context. Spatial coordination is implemented in the auction by building in additional rewards based on the proximity of individual forest plots to the NP: ecological benefits per enrolled plot are assumed to be higher if that plot is adjacent to the NP. Second, additional rewards are also associated with enrolled plot connectivity, since the creation of enrolled corridors is assumed to facilitate the movement and migration of wild animals. Both proximity and connectivity increase the score given to a bid by increasing the value of an environmental metric. A forest-related (rather than a neutral) framing is used to make the situation more realistic for the subjects, and to help them understand this relatively complex design.

\subsection{Design}

Participants of the experiment were divided into groups of 6 (typically, there were 18 subjects in each session). Each of these participants was assigned a "property" consisting of 16 plots (see Figure 1 showing the initial information displayed to subject owning plots A3-D6, the 
white lines delineating each player's property). Each property was a $4 \times 4$ square, except for the subject holding A1-D2 and A11-D12 squares, although this makes no strategic difference. Each plot had a specific production value (PV) in experimental dollars (ED), drawn independently from a uniform distribution on $(50,150)$ that could be realized if that particular plot was retained by the owner at the end of the experiment. Each owner could also offer any subset of his plots at any plot-specific prices expressed in ED he wished at a single multi-round auction run by an automated government (with total rounds determined by the stopping rule).

$<$ FIGURE 1>

In each round, the government would "provisionally purchase" a combination of plots offered by some or all the sellers that would maximize environmental value (EV) per experimental dollar spent on purchases, subject to the constraint that at least $80 \%$ of the government budget of 5,000 ED was spent. ${ }^{1}$ The Environmental Value of any combination of plots that could be purchased was calculated as follows:

- one point for each plot purchased in columns A-F,

\footnotetext{
1 Forcing the government to spend some specific amount precisely would easily lead to poor results (in terms of EV per ED spent). On the other hand, real public agencies obviously operate within budget restrictions. Furthermore, avoiding any constraints could result in strong between-round volatility of plots provisionally purchased. Of course, the specific range used in the experiment is quite arbitrary.
} 
- two points per plot purchased in columns G-H (the EV of these plots adds the national park proximity bonus of one unit to the score allocated to other plots).

- An additional one point connectivity bonus for each two purchased plots sharing a vertical border i.e. constituting a horizontal corridor. The EV connectivity bonus does not take into account whether the plots belonged to the same or to different participants.

An example may be helpful. Let's assume the government buys plots $6-D, 6-E, 7-E, 7-F$ and 7-G the total environmental value (EV) equals:

1 [for 6-D] +1 [6-E] +1 [7-E] +1 [7-F] + 2 [7-G is in the buffer zone] + 1 [ connectivity bonus for adjacent 6-D and 6-E] +1 [connectivity bonus for adjacent 7-E and 7-F] +1 [connectivity bonus for adjacent 7-F and 7-G] $=9$

In setting these rules we were trying to mimic some characteristic features of real landscapes, and the ecological factors determining the delivery of ES and biodiversity conservation. First, the plots close to the existing National Park were considered more valuable. Second, the creation of corridors stretching out of the National Park, facilitating movements and migration of wild animals was rewarded. By assigning one of the owners a discontinuous A1-D4, A11-D12 property we have made sure that each participant had exactly two neighbors with whom to construct horizontal corridors - the situation was strategically identical for each of the three A-D owners and similarly among the three E-H owners. 
The experiment ended for the group if the environmental value per ED spent improved by no more than $5 \%$ in each of 5 consecutive rounds. ${ }^{2}$ The provisional purchases would then become actual purchases and the subjects would earn the amount in ED resulting from adding up the production values of un-contracted plots and the transaction prices of contracted plots. This was then exchanged into Polish Zloty (zł) at the rate of $1 \mathrm{ED}=0.015 \mathrm{z} \nmid$ (ca. 4 eurocent). If a round was not the final one, the offers made in it had no direct impact. However, they would become default offers in the subsequent round. These default offers could then be altered, removed or augmented with offers for previously un-offered plots at each subjects' discretion.

\subsection{Subjects' information sets.}

Subjects were presented with a map showing the private forest properties and the boundary of the state-owned national park. Every participant knew all production values of their own but not that of others' plots (see Figure 1$)^{3}$. Respondents were informed that the

2 We wanted to make sure that the experiment would not run for too long. Therefore, the maximum number of rounds was set at 30 - it would end automatically if the endogenous stopping rule was not applied earlier.

3 Lack of information about the other owners' private production values can be explained by several factors. In many European countries forests are not homogeneous in terms of structure and age of the trees. Forest owners can more easily estimate the production value of adjacent, relatively small and homogeneous forests plots, but such estimations are more difficult when forests parcels are larger, heterogeneous or located farther away. Additionally, for the forest owners the value of the forest or its individual fragments may comprise not only on the 
automated government had a budget of 5000 ED which it would try to spend (or slightly less) by buying the plots offered by subjects in a way to maximize the joint environmental value. They also knew that the government wanted to achieve a high environmental value from the auction and - crucially - how this environmental value was calculated via the metric. After each round, subjects were shown all subjects' bids and their spatial location. ${ }^{4}$ The bids were marked in a way to distinguish provisional winners from losers (see Figure 2). Subjects were not informed about the exact stopping rule - they were told that each round could prove to be the last one (and thus its results would matter for real). An example of the experimental instructions (for the treatment combination: Discriminatory and chat) can be found in the Appendix to this paper.

$<$ FIGURE 2>

production value but also be made up of non-market values including recreational, aesthetic, existence, and bequest values), which are difficult for others to calculate. Finally, variation in forest owners' willingness to accept (WTA) may also result from various additional factors, including changes in their economic situation not necessary known by their neighbors. To allow for non-market values and external factors that may affect the WTA without introducing additional elements to the experimental design, we decided that owners' private production values of plots would be unknown for other subjects. In the literature we also find examples of using a similar approach. Cason and Gangadharan (2005), among others, do not reveal other bidders' cost either.

4 This could be considered a highly stylized feature. One reason for implementing it is that it facilitated learning in a field application subjects would have more time and stronger incentives to understand the scheme and develop their strategy. They could also make use of professional advisors. 


\subsection{Experimental treatments}

Each group of participants operated under one of two auction formats. In the Discriminatory Pricing (DP) condition, each accepted plot would be purchased at the price offered. Under the Uniform Pricing (UP) condition, all purchases in columns A-F had to be made at the same price. Similarly, all plots purchased in columns G-H would be bought at the same price. We chose to impose two Uniform prices to indicate that plots in columns G-H are more valuable for the government than other plots, as they constitute a buffer zone for the national park. This information was provided to subjects in the instructions. Setting two different Uniform prices (higher for the plots in the buffer zone) should lead to an increased number of offers from plots with a higher environmental values (columns G-H).

We also varied the availability of chat: in around half the groups subjects were allowed to send any chat message to any combination of other participants at any time, both before and after submitting their offers in given round. In the no-chat condition, no communication was allowed whatsoever. Table 1 shows the number of groups in each of four resulting treatments.

$<$ TABLE 1>

\subsection{Procedures}


The experiment was conducted in the spring of 2013 at the Laboratory of Experimental Economics at the University of Warsaw, using the local (student) subject pool. It was computerized using a Python-based program. ${ }^{5}$ Printed instructions were used. Both software and instructions were developed in pilot sessions to ensure that subjects had no problem understanding their decision environment. 11 sessions with 1 to 3 groups each were run. A short post-experiment questionnaire was deployed to collect demographic data. Table 2 shows the descriptive statistics of the sample.

$<$ TABLE 2>

The median number of rounds equaled 7 in the DP condition, whereas it was higher (13) under the UP condition. In both the Chat and No Chat conditions, the median number of rounds was 9.5. Uniform pricing with Chat (UPC) sessions lasted longest (106 minutes on average), corresponding figures for other treatments were 63 minutes, 48 minutes and 38 minutes for Discriminatory pricing with Chat (DPC), Uniform pricing with No Chat (UPNC), and Discriminatory pricing with No Chat (DPNC) respectively. In one case, a UPC group ended after round 30 without converging.

\section{5. Performance Measures}

5 The program was developed by Jean-Marc Rousselle of INRA-LAMETA. 
Because the decision making environment was relatively complex, we thought it worthwhile to first establish that subjects' behavior followed rules that would seem economically reasonable. First, there is little reason to bid below an individual plot's production value, as this can only mean selling at a loss (and if meant to increase the environmental value of an adjacent plot of the same player, being offered at above its production value, then the price of this adjacent plot could be reduced instead). ${ }^{6}$ Another check of subjects' ability to respond to strategic incentives would be to compare the bids for different columns of each owner's property - we will refer to columns A,D,E and H as "outer columns" and B,C,F and $G$ as "inner columns". Because of the horizontal connectivity bonus, it would on average be more important to have an offer in an inner column accepted, compared to an offer in an outer column, because the former would increase the attractiveness of two of the same owner's plots, while the latter would only help one offer. We thus expected more competitive bids in the inner columns. ${ }^{7}$ Finally, given that the plots in columns $\mathrm{G}$ and $\mathrm{H}$ had higher environmental values, we would expect these subjects to seize the opportunity and require higher profit margins (defined as the difference between the bid and the production value).

\footnotetext{
6 This is true for all the treatments, but such behaviors are expected to happen more often under uniform pricing, where they are more often harmless in terms of player's payoff. This is indeed the case if the resulting uniform price is higher anyway.

7 The comparison is slightly complicated by the fact that $\mathrm{G}$ and $\mathrm{H}$ provided higher environmental value but this is orthogonal to our definition of "inner" or "outer" columns.
} 
After passing this stage we can focus on our major goal: analyzing the auction treatments' influence on revenue and efficiency. In a standard auction, revenue maximization involves securing high prices for the objects on sale. In our setting of a multi-unit procurement auction, the counterpart is that the government seeks to minimize the average price paid per unit of EV, or equivalently to maximize EV per dollar spent. These measures do not account, however, for possible differences in production values between groups. ${ }^{8}$ If, by chance, plots with low production values tended to be relatively numerous, clustered in horizontal corridors and situated next to the national park in, say, UPNC groups, it would be easier to obtain high EV per ED values compared to other treatments. This corresponds to a situation in a real landscape

8 On one hand side, using exactly the same production values in all the groups could have improved the comparability of treatments. However, there would be some disadvantages to that as well. First, as a general rule in our lab, we try to make sure that subjects have as little incentive as possible to discuss the experiment with peers, so that those who have already taken part do not influence those who are about to take part. We therefore prefer to change parameters across sessions, if it is reasonable given the specific design of the experiment. We also follow the policy of no deception, so subjects would have to be informed that numbers have been pre-determined, which in some of them could raise suspicion that they were never truly randomized. Additionally, if production values were identical in all groups, then the validity of results could be reduced. According to a reviewer's suggestion we have run nonparametric tests to verify if designs varied between treatments in terms of PV and EV (the availability to create corridors). We have not found significant differences between DP and UP or between Chat and No chat conditions. 
where land with higher ecological potential also has the lowest opportunity costs of enrollment; or where there is a particular pattern of spatial correlation of opportunity costs across sites (Armsworth et al., 2012). For this reason we have also calculated relative EV, whereby we divided the EV per ED by the highest possible EV per ED obtainable under the counterfactual assumption that every plot could be purchased at its true production value. The logic behind this procedure is that no owner should be forced to sell at a negative profit.

Differences in relative EV (if any) could be decomposed into three elements, each of which we therefore analyze separately. First, profit margins (PM) from the final round of the experiment (and as a result subjects' earnings) could differ across treatments. Second, treatment effects could be due to differences in the mechanism's ability to encourage coordination of conservation efforts, resulting in horizontal corridors of adjacent plots purchased. The total value of connectivity bonuses appears to be the most appropriate simple aggregate measure in this respect. Finally, the total value of NP proximity bonuses paid can differ across treatments. Finally, regarding auction efficiency, the regulator's preference is assumed to be that ecosystem services are provided by agents whose true costs (supply prices) are lowest. In our case, the natural measure is EV obtained per 1000 ED lost in terms of foregone production value. Table 3 summarizes these measures and their detailed descriptions.

<Table 3.> 


\section{Results}

\subsection{Rationality of individual behavior}

We have argued that there were limited incentives to bid below an individual plot's production value. It is thus reassuring to see that such choices were rare. An average bidder in the DP made 13.86 offers above the relevant PV of his plots and just 0.21 and 0.41 offers at or below it respectively (meaning that 1.52 plots on average would not be offered at all). Corresponding figures for the UP were 10.69, 1.98, 1.03 and 2.30 (note that, in line with our expectations, offers at or below PV were more common here). Figure 3 shows the distribution of bids under Discriminatory and Uniform Pricing.

$<$ FIGURE 3>

Next, we hypothesized that more competitive bids would be made for plots located in the inner columns. To verify this claim, each plot was treated as an independent observation. We find that relative offer is indeed modestly higher for "outer" than "inner" columns: 1.433 vs. $1.414(p$-value $=0.1527)$ in DP and 1.367 vs. $1.247(p$-value $=0.0473)$ in UP.

We also expected subjects to seize the opportunity and require higher profit margins for the plots in the NP buffer zone. It turns out this is the case: when compared to plots in columns $E$ and $F$ (i.e. owned by the same subjects), the relative offers are much higher. With 
discriminatory pricing in the NP buffer zone, the mean of relative offers equals 1.664 , whereas outside the NP zone the mean is significantly lower at 1.337 ( $p$-value<0.0001). Under uniform pricing these values equal respectively 1.367 and 1.247 , and are significantly different from each other ( $p$-value<0.0001).

\subsection{Environmental revenue maximization}

To examine the impact of auction format and the availability of communication on environmental revenue maximization, we examine differences in EV per $1000 \mathrm{ED}$ spent and the relative EV measure, as well as connectivity and NP proximity bonuses. The mean value of the first three indicators are highest under Discriminatory Pricing with communication, whereas the lowest values of EV per 1000 ED spent and relative EV measure are calculated for UP without chat. Statistics of all auction characteristics in the final round are presented in Table 4.

$<$ TABLE 4>

In order to examine the treatments' performance we recognize the interdependence of bids within the same group and perform all the statistical tests on the group level. Due to the small sample size, we decided to use Mann-Whitney non-parametric tests. Table 5 and Table 6 show the test results for those measures. 
$<$ TABLE 5>

$<$ TABLE 6>

The relative EV and EV per 1000 ED spent measures indicate that Discriminatory Price auctions are marginally superior to Uniform Price auctions (for the first measure: $p$-value $=0.0378$ and the other: $p$-value $=0.0545)$. Additionally, the total value of connectivity bonuses is substantially higher for the DP treatment than under UP ( $p$-value $=0.0001)$. This is largely due to longer corridors being built, with the average corridor length being 3.59 plots under DP and only 2.75 under UP. For example, there are eight maximal corridors (i.e. those of length 8) in DP groups and only one in the UP groups.

To understand why UP makes the formation of long conservation corridors very rare, consider the example shown in Figure 1. It is nearly impossible to purchase B6 under Uniform prices - because of its high production value, even a modest price markup would require all plots (not adjacent to the NP) to be purchased at a very high price. This is similar to the "hold out" problem considered by Lennox et al. (2012). Thus, just one high-PV plot essentially excludes complete corridors in given row. On the contrary, if A6 and C6 are to be purchased under a DP regime, it can be optimal for the government to additionally purchase B6, provided its owner is satisfied with a small profit margin on this plot. 
$<$ FIGURE 4>

We also look at the evolution of the relative EV as bidding rounds progressed. As shown in Figure 4, there is a generally-increasing trend in all four treatments. This is particularly strong in early rounds, with relatively little further change after round 6. Overall, there seems to be little evidence to make a case for a systematic premature stopping mechanism. Likewise, only one group (represented in green on the bottom right panel of Figure 4) saw a final relative EV substantially lower than in some (here: two) of earlier rounds. We also note that Uniform Price auctions typically show substantially higher volatility, which explains why they lasted longer. One possible explanation of such a pattern is that in the Uniform Price treatment, changing just one offer (the marginal one) can affect the amount paid for all the items that are purchased (in our case: all the other plots near the National Park or all the other plots far from the National Park). By contrast, in the Discriminatory Price treatment, changing one offer does not affect the profit margin on other offers: even if several changes are made, typically some will decrease and some will increase profit margins.

As for the role of communication, Chat has no impact on EV per 1000 ED spent ( $p$-value $=0.1985)$ or relative EV ( $p$-value=0.1498), although it might have facilitated the creation of long corridors. This is visible under DP, where the difference in connectivity bonuses between the Chat and No Chat versions is statistically significant ( $p$-value $=0.0210$ ). However, this effect is 
not observed in UP treatment. This lack of effect is partly due to the fact that it was more difficult to create long corridors with uniform pricing. The availability of communication between subjects also seems to have led to somewhat higher NP proximity bonuses (DP: p-value=0.0196 and UP: $p$-value=0.0714). In this case, we were expecting the opposite effect, predicting that with the availability of communication, subjects owning plots in the buffer zone would collude, and so as a result fewer NP proximity bonuses would be created.

The other measures which can be used to examine auction performance are profit margins and subjects' earnings from the experiment. Analyzing these measures we do not find any significant difference in profit margins and earnings between DP and UP ( $p$-value equals 0.2931 and 0.7005 , respectively). This is in contrast to findings of Cason and Gangadharan (2005) who observed superior performance in the discriminatory price treatment. It would thus appear that their finding is not robust to the (substantial) differences in the design of the two studies. The availability of communication also seems to not have an effect on profit margins ( $p$-value $=0.6070)$ and the subjects' earnings ( $p$-value=0.7576).

\subsection{Efficiency in providing environmental services}

The other objective we focus on is the impact of treatments on auction efficiency, which requires environmental services being provided from plots with the lowest opportunity costs (production values foregone). As the main auction efficiency indicator we use EV obtained per 1000 ED lost in terms of foregone production value. We do not have a natural "ideal" 
benchmark here, because it is not clear how much each unit of EV is worth. We can, however compare efficiency across treatments. Table 7 and Table 8 show the test results for this measure.

$<$ TABLE 7>

<TABLE 8>

We do not observe a significant difference in EV per 1000 ED of production value lost between DP and UP treatments ( $p$-value=0.1178). Recall that EV per 1000 ED spent was relatively low under UP largely because heterogeneity in PV made it difficult to purchase adjacent plots in this auction format, resulting in lower connectivity bonus. However, the fact that high-PV plots do not get purchased under UP is not necessarily bad from the viewpoint of EV per 1000 ED of PV lost. It is thus not surprising that UP does no worse than DP in terms of auction efficiency. Chat seems to cause a marginally significant, positive effect on efficiency measured as EV per 1000 ED of production value lost ( $p$-value=0.0506). This finding is largely in line with our speculation concerning the impact of communication. To the extent that chat 
facilitates coordination, it helps raise efficiency, while its impact on price does not have a direct detrimental effect on this dimension. ${ }^{9}$

\section{Conclusions}

This study adds to the growing literature investigating how one achieves spatial coordination in conservation auctions (Polasky et al., 2014; Banerjee et al.,2014b; Windle et al., 2009; Rolfe et al., 2009; Reeson et al., 2011). Spatial coordination has been argued to be important ecologically in terms of the creation of wildlife corridors and in creating "big enough" contiguous areas of enrolled in conservation schemes (Bartelt et al., 2010; Carvell et al., 2007). Given the increasing interest in how to design Payment for Ecosystem Services in contexts where spatial ecological concerns matter, our paper also offers valuable insights to policy

9 We have decided not to conduct the formal qualitative analysis of communication between subjects, for the following reasons. First, chat contents is often subject to potentially diverging interpretations and it is (unlike assignment to chat treatment) clearly endogenous. One must thus be very careful when claiming that threats and promises enhance cooperation or collusion. Moreover, even if such effects exist, they have limited practical implications -- auction organizers can try to prevent all communication (during the auction) but it is much harder to only allow some types of messages (e.g. only those calling for better spatial coordination but not price collusion etc.). Several experimental papers allowing free-form communication do not have a systematic analysis of its contents. Examples include studies by Brosig et al. (2003), Bochet et al (2006), or Ben-Ner and Putterman (2009). We thus decided not to pursue this option. We think this approach is particularly justified in the case of our study since chat has very little impact on most measures of auction performance. 
designers interested in using conservation auctions to achieve such spatially-dependent outcomes in a more cost-effective manner.

We use a laboratory experiment to explore two features of auctions for the provision of ecosystem services where spatial coordination is important to environmental benefits. First, we compare Uniform and Discriminatory Pricing mechanisms. Second, we investigate the influence of communication between subjects. As far as we are aware, ours is the first study examining both of these aspects in the context of spatially-integrated conservation auctions. We conduct our analysis in the context of a forest landscape where the environmental benefits of land being offered into a conservation scheme depends on its location (Parkhurst and Shogren, 2007). Two different aspects of space are explicitly recognized in the design of the environmental metric used to weight bids. These are the proximity of enrolled plots to a national park - assumed to be of high ecological value - and connectivity associated with the creation of continuous corridors of enrolled plots. Our study extends previous analysis by accounting for heterogeneity in the production value of plots and incomplete information concerning the value of the other subjects' properties. Finally, we use an automated, endogenous stopping rule which gives incentives to subjects to carefully consider all of their bids as the auction progresses.

The results show that choice of auction format makes a difference in the performance of conservation auctions. In particular, the government (the buyer) obtained higher environmental value per dollar spent in Discriminatory Price auctions compared to a Uniform Pricing rule. The DP format also resulted in the creation of longer corridors, possibly because it avoids the hold-out problem which the UP format faces when a high supply price landowner is located at a 
spatially critical point. However, there was no overall significant improvement in auction efficiency from the DP format. The option to communicate with other players had little impact in the experiment, other than on corridor length, where the direction of effect differed between the DP and UP treatments.

In thinking about limited information concerning the production value of the other subjects' plots, it is worth pointing out that from an individual landowner's perspective the Uniform Price strategy demands less cognitive effort than the Discriminatory Price auction. In real life situations, this may translate into lower costs associated with hiring consultants to help determine bids, and thus lower transactions costs and greater participation. Moreover, communication between subjects may facilitate spatial coordination, improving environmental outcomes and thus overall efficiency.

Communication between sellers, in theory, can also have the opposite effect, promoting collusion which is specifically aimed at increasing information rents. In this case, the minimization of costs is not achieved. There is thus a fundamental trade-off between the beneficial environmental effects of communication and the adverse effects of communication on bid prices. Our experimental design, however, does not allow us to adequately parse between these effects.

Clearly, our experimental setup has its limitations. It would be desirable to replicate our findings with experienced bidders such as actual forest owners, with more time for reflection and with higher stakes. It would also be useful to investigate the extent to which these findings 
carry over to other types of spatial coordination problems (other environmental metrics); and to situations where the benefits of conservation actions depend not just on spatial coordination but also on the characteristics of individual plots (e.g. their land use history, elevation or soil type). The environmental benefits from a set of actions contracted on a given plot might also depend on land use patterns at the local landscape level, additionally to any spatial coordination effects (Dallimer et al., 2010). We also note evidence for the US Conservation Reserve Programme of a decline in auction performance over time, which might be due to bidders learning more about each other's offers over time, and so shading their individual bids upwards on average (Kirwan, 2005; Cowan, 2010). Other reviews of actual conservation auction schemes show a complex set of drivers of landowners' motivations to participate in such schemes, and how to formulate their bids (Whitten et al, 2015)

If the experimental results reported here prove robust, Discriminatory Price auction formats should be preferred in PES settings resembling those simulated here, where spatial connectivity plays a major role in the delivery of environmental benefits. However, what has not been addressed here is the relative performance of a spatially-targetted Discriminatory Price auction compared to an agglomeration bonus scheme, as implemented for example in Banerjee et al (2014a). It is also unclear how the relative net benefits of these two mechanisms will compare in different ecosystem service and biodiversity conservation settings.

In our experiment we used a forest decision-making context, even though we realize that contextualizing experiments may substantially alter subjects' behavior. The results may then poorly generalize to other contexts. However, we have no reason to believe that a 
"forest-framing" effect - even if present in this experiment - results in a systematic distortion of the treatment effects we are mostly concerned with. If, for example, subjects value biodiversity and so instinctively support deriving ecosystem services from forested land (even if it is only a frame in a game with purely monetary payments), this might lower the prices they are asking, but there is little reason to think that this will only occur in the uniform but not discriminatory treatment, or vice versa. Therefore, our results concerning the statistical differences between auction formats can be, in our opinion, generalized to the broader category of conservation auctions, despite the specific framing of decisions in this experiment. What is more, not invoking a specific forest decision-making context in a study such as ours, which concerns an issue which many people are not familiar with, could decrease participants' understanding of the nature of the payoffs associated with the decisions to be undertaken by them in the experiment. This lack of understanding of the decision problem at hand would decrease the reliability of the results obtained.

Finally, we note that forests are a good example of the importance of spatial coordination for many ecosystem service and biodiversity conservation objectives. For instance, improving forest resilience against invasive pests and diseases requires spatially-coordinated actions by multiple private forest owners in much of Northern Europe. Forests thus make for a very relevant context in which to set the experiment, given our desire to be able to produce research which is relevant to actual conservation policy design. 
Acknowledgments: We would like to thank Jean-Marc Rousselle who had developed software used in this experiment and Marta Dyrkacz who provided research assistance. The study was carried out as a part of the NEWFOREX project (New Ways to Value and Market Forest Externalities, FP7-KBBE-2009-3, Project no. 243950). Funding support is gratefully acknowledged. We thank several referees for their insightful comments on earlier versions of this paper; and participants at the 2014 Bioecon conference. 


\section{References:}

Ajayi, O. C., Jack. B. K., Leimona, B. 2012. Auction Design for the Private Provision of Public Goods in Developing Countries: Lessons from Payments for Environmental Services in Malawi and Indonesia, World Development, 40(6), 1213-1223.

Armsworth, P., Acs, S., Dallimer M., Gaston K., Hanley, N., Wilson, P. 2012. The costs of simplification in conservation programmes. Ecology Letters 15 (5), 406-414.

Balliet, D. 2010. Communication and cooperation in social dilemmas: a meta analytic review. Journal of Conflict Resolution 54, 39-57.

Bamière, L., David, M., Vermont, B. 2013. Agri-environmental policies for biodiversity when the spatial pattern of the reserve matters. Ecological Economics 85, 97-104.

Banerjee S., A. M. Kwasnica and J. S. Shortle. 2012. Agglomeration Bonus in Small and Large Local Networks: A Laboratory Examination of Spatial Coordination. Ecological Economics, Volume 84, pp. 142 - 152.

Banerjee S., deVries, F., Hanley, N., van Soest, D., 2014a. The impact of information provision on Agglomeration Bonus performance: An experimental study on local networks, American Journal of Agricultural Economics, Volume 96(4), pp. 1009-1029

Banerjee, S., Kwansica, A., Shortle, J. 2014b. Information and auction performance: conservation auctions for spatially contiguous land management. Environmental and Resource Economics, DOI 10.1007/s 10640-014-9798-4.

Bartelt, P., Klaver, R., Porter, W. 2010. Modeling amphibian energetics, habitat suitability, and movements of western toads across present and future landscapes. Ecological Modelling 221(22), 2675- 2686.

Ben-Ner, A., Putterman, L. 2009. Trust, communication and contracts: An experiment. Journal of Economic Behavior \& Organization, 70(1), 106-121. 
Bochet, O., Page, T., Putterman, L. 2006. Communication and punishment in voluntary contribution experiments. Journal of Economic Behavior \& Organization, 60(1), 11-26.

Brosig, J., Weimann, J., Ockenfels, A. 2003. The effect of communication media on cooperation. German Economic Review, 4(2), 217-241.

Carvell, C., Meek, R., Pywell, F., Goulson, D., Nowakowski, M. 2007. Comparing the efficacy of agrienvironment schemes to enhance bumble bee abundance and diversity on arable field margins. Journal of Applied Ecology 44(1), 29-40.

Cason, T., Gangadharan, L., 2005, A laboratory comparison of Uniform and discriminative price auctions for reducing non-point source pollution, Land Economics, vol 81, pp. 51-70.

Cowan, T. 2010. Conservation reserve program: status and current issues. In United States Department of Agriculture. http://crs.ncseonline.org/nle/crsreports/10Oct/RS21613.pdf.

Cong, R-G, Wei, Y-M. 2010. Auction design for the allocation of carbon emission allowances: Uniform or Discriminatory price? International journal of energy and environment 1(3) 533-546.

Dallimer, M., Gaston, K., Skinner, A., Hanley, N., Acs, S., Armsworth, P. 2010. Field level bird abundances are enhanced by landscape level agri-environmental scheme uptake. Biology Letters 6, 643-646.

Ferraro, P. J. 2008. Asymmetric information and contract design for payments for environmental services. Ecological Economics 65, 810-821.

Friedman, M. 1991. Wall Street Journal of 28 August, 1991.

Hailu A. and Thoyer S., 2010. What Format for Multi-Unit Multiple-Bid Auctions? Agent-Based Simulation of Auction Performance and Nonlinear Bidding Behaviour. Computational Economics. 35: 189-209. 
Hanley, N., Banerjee, S., Lennox, G., Armsworth, P. 2012. How should we incentivise private landowners to "produce" more biodiversity? Oxford Review of Economic Policy 28 (1), 93-113.

Iftekhar M.S. and J. Tisdell (2015) "An Agent Based Analysis of Combinatorial Bidding for Spatially Targeted Multi-Objective Environmental Programs." Environmental and Resource Economics, DOI 10.1007/s10640-015-9882-4

Kahneman, D., Knetsch, J. L., Thaler. R. "Fairness as a constraint on profit seeking: Entitlements in the market." The American economic review (1986): 728-741.

Kirwan, B., Lubowski, R., Roberts, M. 2005. How cost-effective are land retirement auctions? Estimating the difference between payments and willingness to accept in the conservation reserve program. American Journal of Agricultural Economics 87(5), 12391247.

Latacz-Lohmann, U., Schilizzi, S., 2005. Auctions for conservation contracts: a review of the theoretical and empirical literature. Report to the Scottish Executive Environment and Rural Affairs Department.

Lennox, G.D., Dallimer, M., Armsworth, P. 2012. Landowners' ability to leverage in negotiations over habitat conservation. Theoretical Ecology 5(1), 115-128.

Parkhurst, G. M., J. F. Shogren, C. Bastian, P. Kivi, J. Donner, and R. B. W. Smith. 2002. Agglomeration bonus: An incentive mechanism to reunite fragmented habitat for biodiversity conservation. Ecological Economics 41 (2), 305-28.

Parkhurst, G., Shogren, J.F., 2007. Spatial incentives to coordinate contiguous habitat. Ecological Economics 64, 344-355.

Polasky, S., Lewis, D., Plantinga, A., Nelson, E. 2014. Implementing the optimal provision of ecosystem services. Proceedings of the National Academy of Sciences. doi:10.1073/pnas.1404484111 
Reeson, A., Rodriguez, L.C., Whitten, S., Williams, K., Nolles, K., Windle, J. and Rolfe, J. 2011. Adapting auctions for the provision of ecosystem services at the landscape scale. Ecological Economics 70 (9), 1621-1627

Reeson, A., Whitten, S. 2014. Designing Auctions for Different Environmental Commodities. CSIRO Sustainable Agriculture Flagship, Canberra.

Rolfe. J., Windle, J., McCosker, J. 2009. Testing and implementing the use of multiple bidding iterations in conservation auctions: a case study application. Canadian Journal of Agricultural Economics 57(3), 287-303.

Rousseau, S., Moons, E. 2008. The potential of auctioning contracts for conservation policy, European Journal of Forest Research 127,183-194.

Schilizzi, S., Latacz-Lohmann, U. 2007. Assessing the Performance of Conservation Auctions: An Experimental Study, Land Economics 83(4), 497-515.

Vickrey, W. 1961. Counterspeculation, auctions, and competitive sealed tenders, Journal of Finance 16, 8-37.

Vogt, N., Reeson, F. Bizer, K. 2013. Communication, competition and social gift exchange in an auction for public good provision. Ecological Economics 93, 11-19.

Whitten, S.M., Reeson, A., Windle, J., Rolfe, J. 2015. Designing conservation tenders to support landholder participation: A framework and case study assessment, Ecosystem Services 6, $82-92$.

Williams, K.J, Reeson, A.F., Drielsma, M.J, Love, J. 2012. Optimised whole-landscape ecological metrics for effective delivery of connectivity-focused conservation incentive payments, Ecological Economics 81, 48-59.

Windle, J., J. Rolfe, J. McCosker, and A. Lingard. 2009. A conservation auction for landscape linkage in the southern desert uplands, Queensland. The Rangeland Journal 31 (1), 127-35. 
Table 1. Experimental treatments: number of groups.

\begin{tabular}{lcc}
\hline Treatment & DP & UP \\
\hline Chat & 6 & 6 \\
No chat & 7 & 7 \\
\hline
\end{tabular}

Table 2. Descriptive statistics of the sample.

Subjects' characteristic

Mean age (in years)

23

Share of females

$52 \%$

Share of students

$84 \%$

Share of subjects with experience in lab

experiments

$62 \%$

Mean net household income (in zł)

5260

Nominal exchange rate $1 €=4.20 z \nmid$ in 2013 . 
Table 3. Description of the measures used.

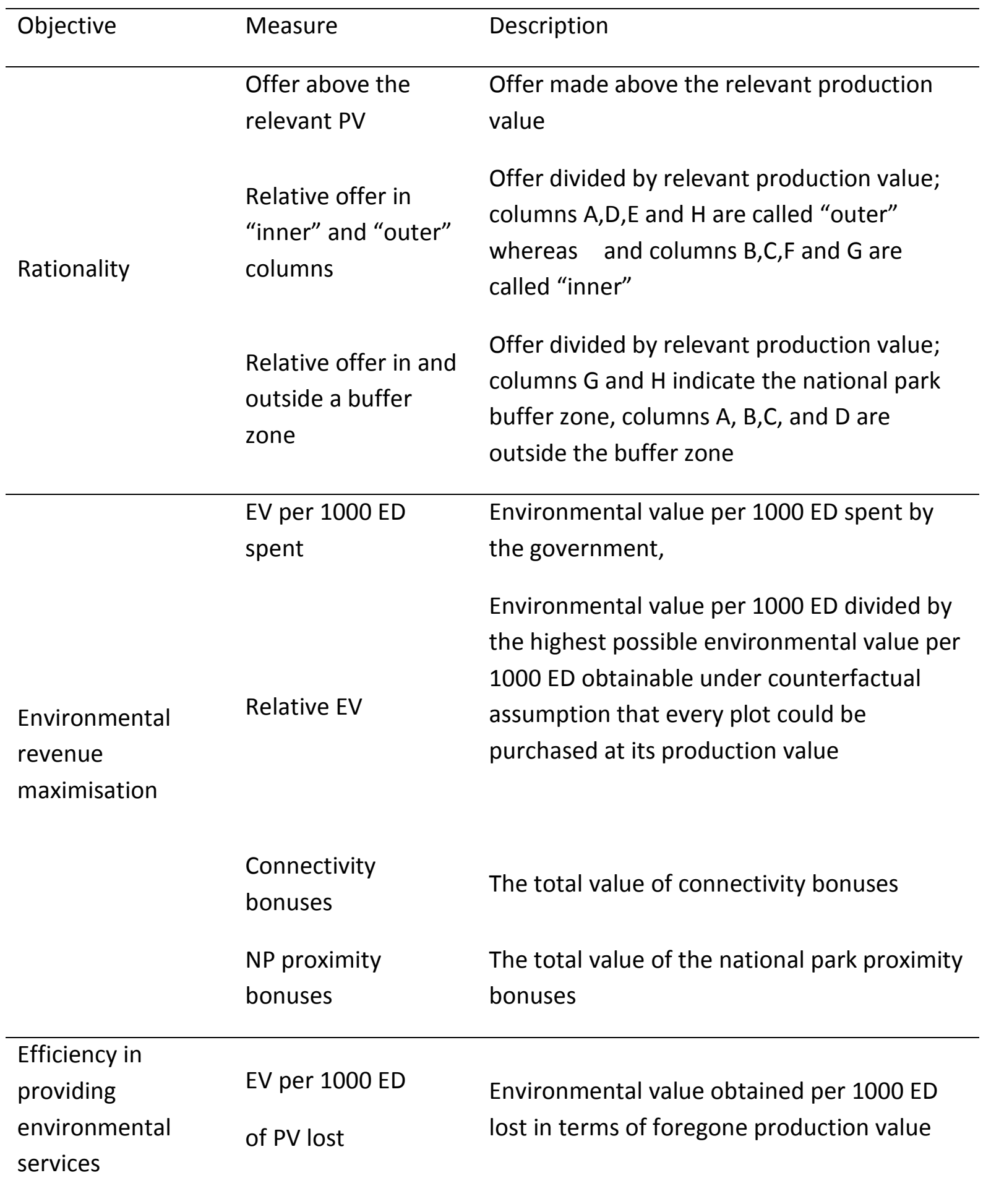


Table 4. Mean values of auction characteristics (final round).

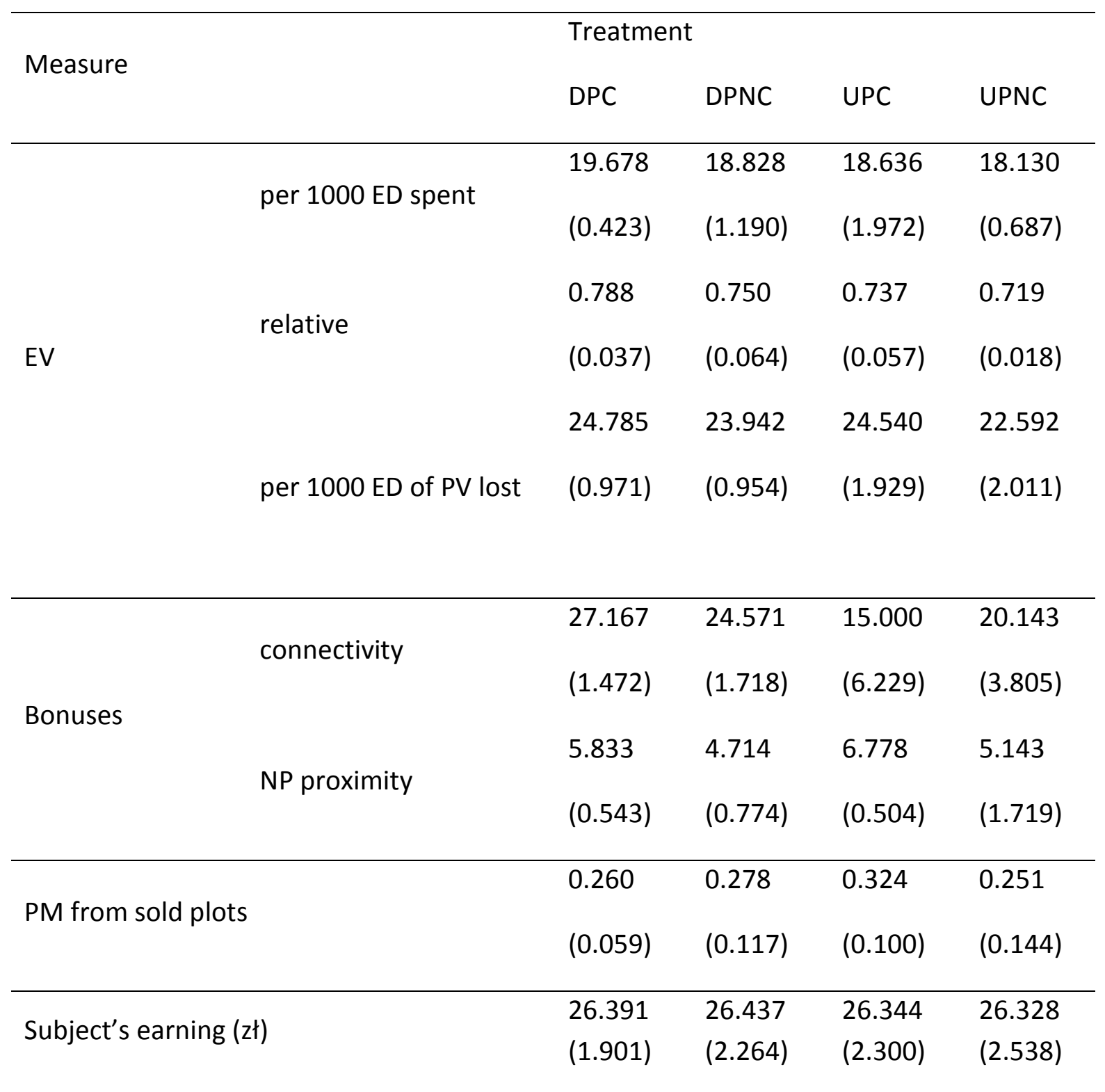

Note: Standard deviations reported in parentheses. 
Table 5. Treatment effects on revenue maximization: Mann-Whitney test results at the group level (final round).

\begin{tabular}{llll}
\hline Treatment comparison & Variable & Z & P \\
& EV per 1000 ED spent & 1.923 & 0.0545 \\
& Relative EV & $\mathbf{2 . 0 7 7}$ & $\mathbf{0 . 0 3 7 8}$ \\
DP vs. UP & Connectivity bonuses & $\mathbf{3 . 8 4 0}$ & $\mathbf{0 . 0 0 0 1}$ \\
& NP proximity bonuses & $\mathbf{2 . 0 1 4}$ & $\mathbf{0 . 0 4 4 0}$ \\
& & & \\
\hline & EV per 1000 ED spent & 1.286 & 0.1985 \\
Relative EV & 1.440 & 0.1498 \\
Chat vs. No Chat & Connectivity bonuses & 0.388 & 0.6982 \\
& NP proximity bonuses & $\mathbf{2 . 6 9 4}$ & $\mathbf{0 . 0 0 7 1}$ \\
\hline
\end{tabular}

Note: Effects significant at $5 \%$ shown in bold. 
Table 6. Partial treatment effects on revenue maximization: Mann-Whitney test results at the group level (final round).

Treatment comparisons

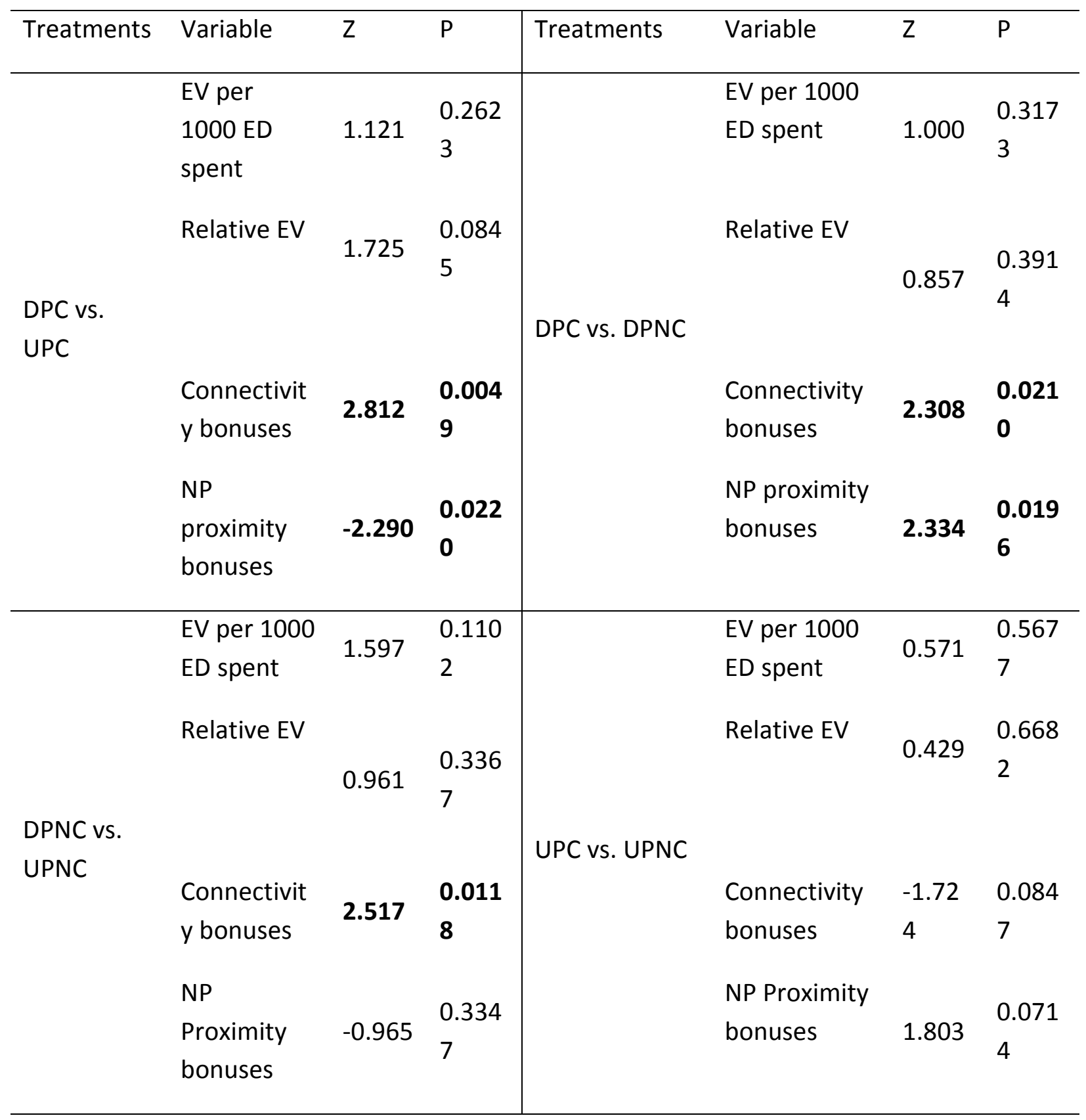

Note: Effects significant at $5 \%$ shown in bold. 
Table 7. Treatment effects on efficiency: Mann-Whitney test results at the group level (final round).

\begin{tabular}{llll}
\hline Treatment comparison & Variable & $Z$ & $P$ \\
\hline DP vs. UP & EV per 1000 ED of PV & 1.564 & 0.1178 \\
Chat vs. No Chat & lost & 1.955 & 0.0506 \\
\hline
\end{tabular}

Table 8. Partial treatment effects: Mann-Whitney test results at the group level (final round).

\begin{tabular}{|c|c|c|c|c|c|c|c|}
\hline \multicolumn{8}{|c|}{ Treatment comparisons } \\
\hline Treatment & Variable & Z & $\mathrm{P}$ & Treatment & Variable & Z & $P$ \\
\hline $\begin{array}{l}\text { DPC vs. } \\
\text { UPC }\end{array}$ & EV per 1000 & 0.961 & 0.3367 & $\begin{array}{l}\text { DPC vs. } \\
\text { DPNC }\end{array}$ & EV per 1000 & 1.571 & 0.1161 \\
\hline $\begin{array}{l}\text { DPNC vs. } \\
\text { UPNC }\end{array}$ & ED of PV lost & 1.469 & 0.1417 & $\begin{array}{l}\text { UPC vs. } \\
\text { UPNC }\end{array}$ & ED of PV lost & 1.429 & 0.1531 \\
\hline
\end{tabular}




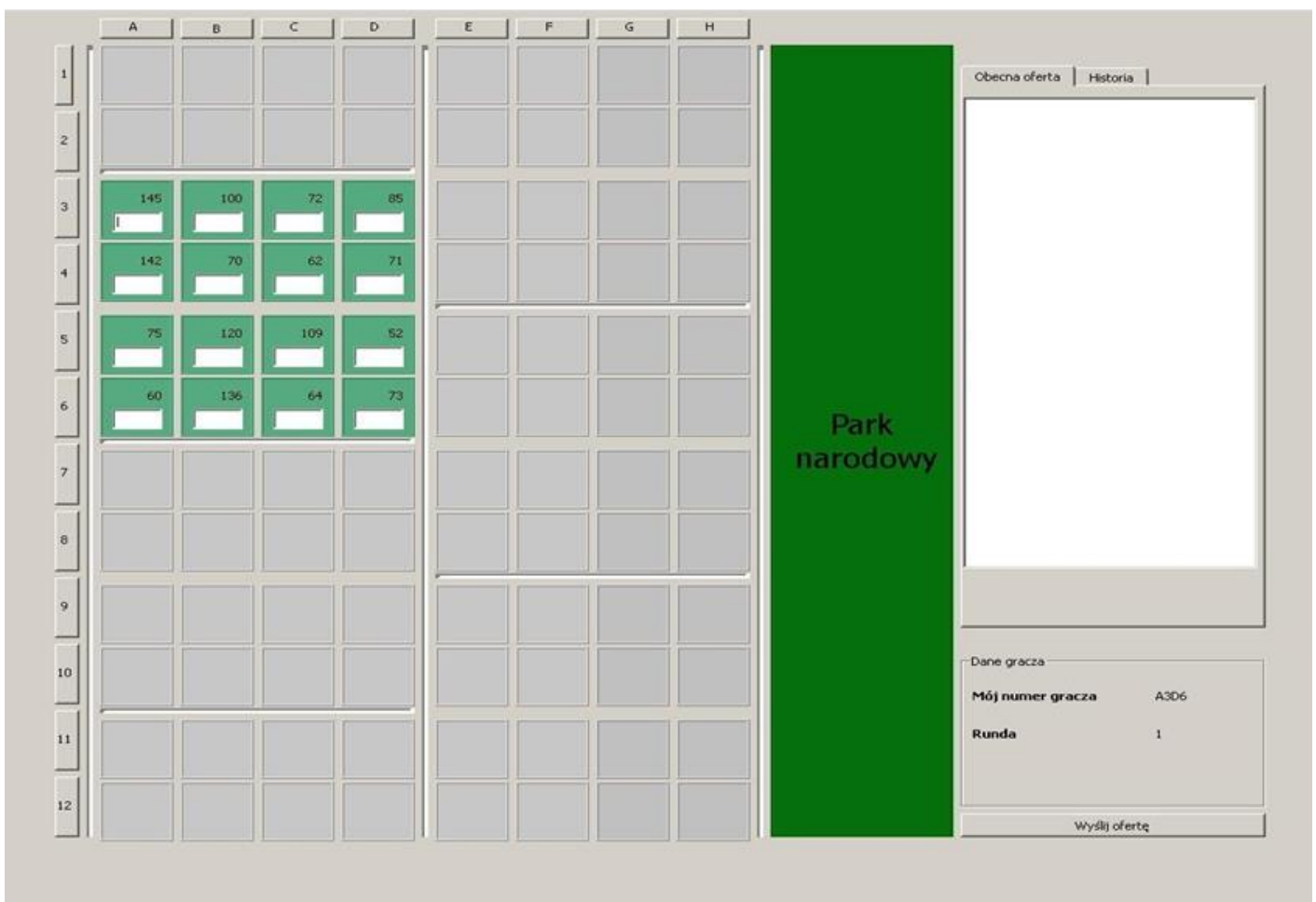

Figure 1. Screenshot showing the initial information displayed to subject owning plots A3-D6. The spatial structure can be considered a torus opened out, as plots A1-D2 and A11-D12 belong to the same subject.

Note: "Park narodowy" means national park in English. Production values are shown in the upper-right corner of each plot. 


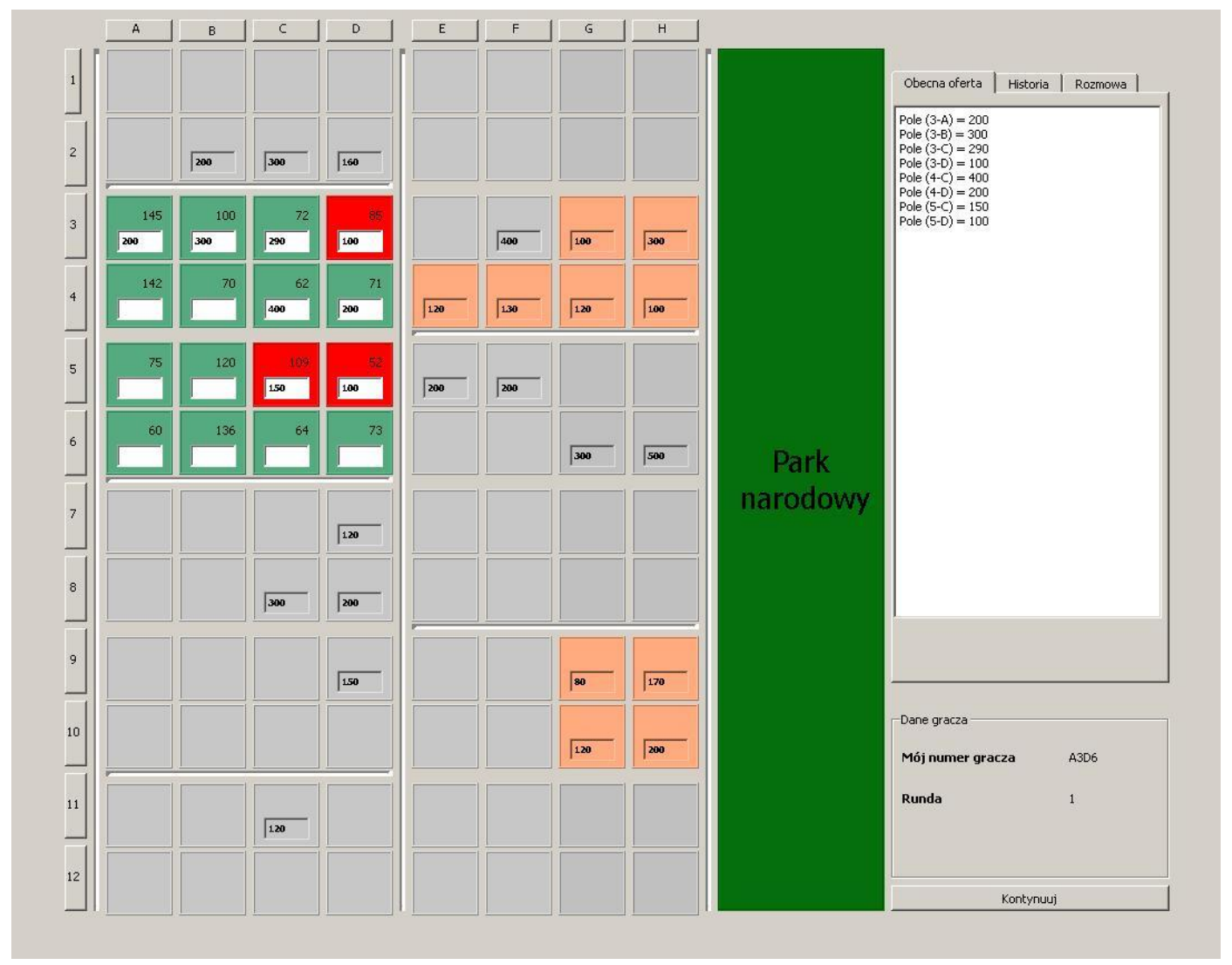

Figure 2. Screenshot showing bids which were provisionally successful at which price (the discriminatory version with chat).

Note: This is an example of the screen shot shown to the participant owning plots A3-D6. The provisionally winning bids from the previous round are marked red for the subject A3D6 and orange for others and shown prior to the start of the next round. Bid levels are displayed in bottom-left corner of each plot. 

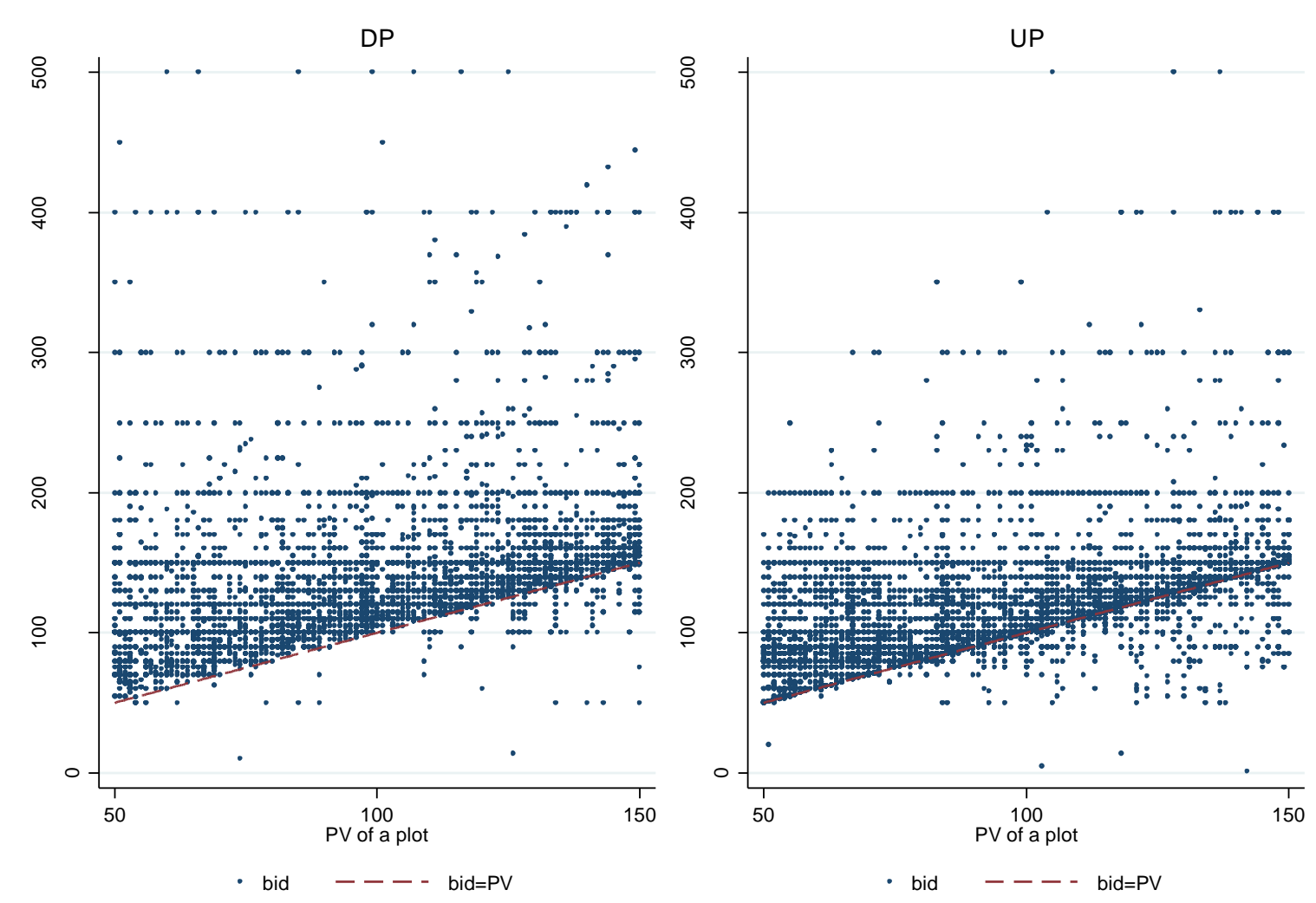

Figure 3. Bids distribution under Discriminatory and Uniform treatments.

Note: Maximum value of a bid was set to 1000 ED. However, as bids higher than 500 ED were very rare, such outliers have been omitted in the figure to improve readability. 
a. DPNC

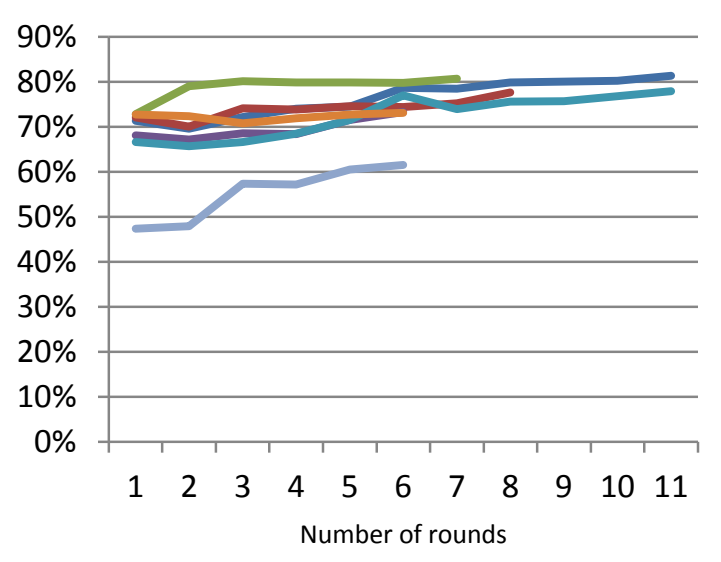

c. UPNC

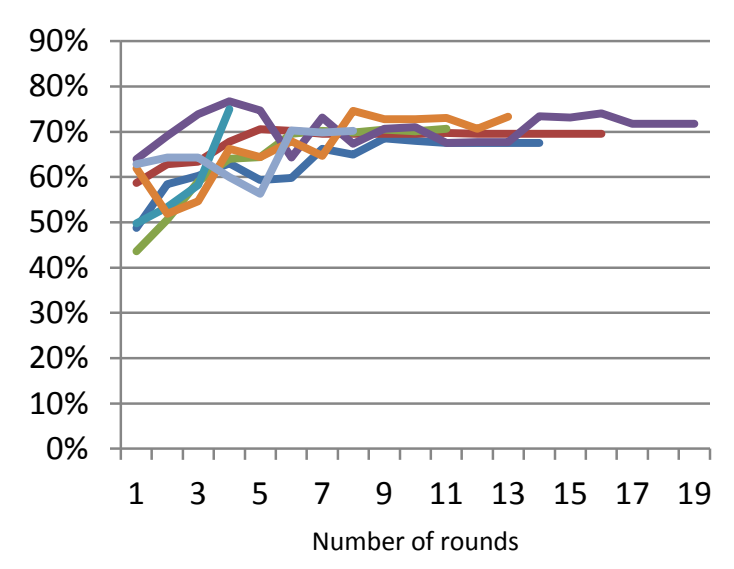

b. DPC

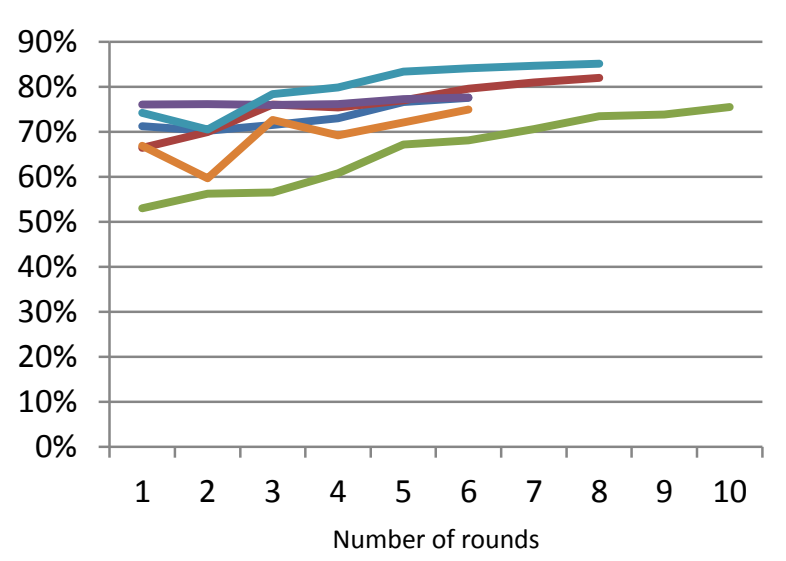

d. UPC

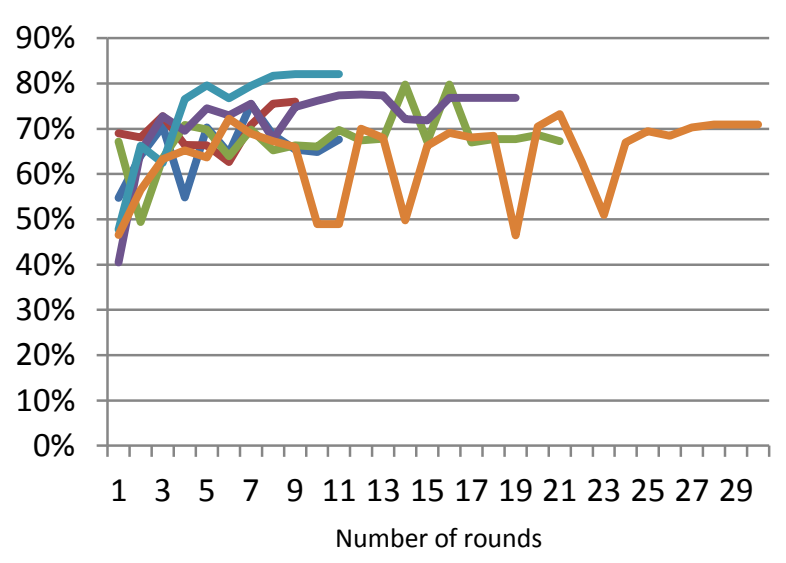

Figure 4. Evolution of relative EV (in \%) over rounds in the particular sessions.

Note: Each session is marked with a different color under one treatment. 


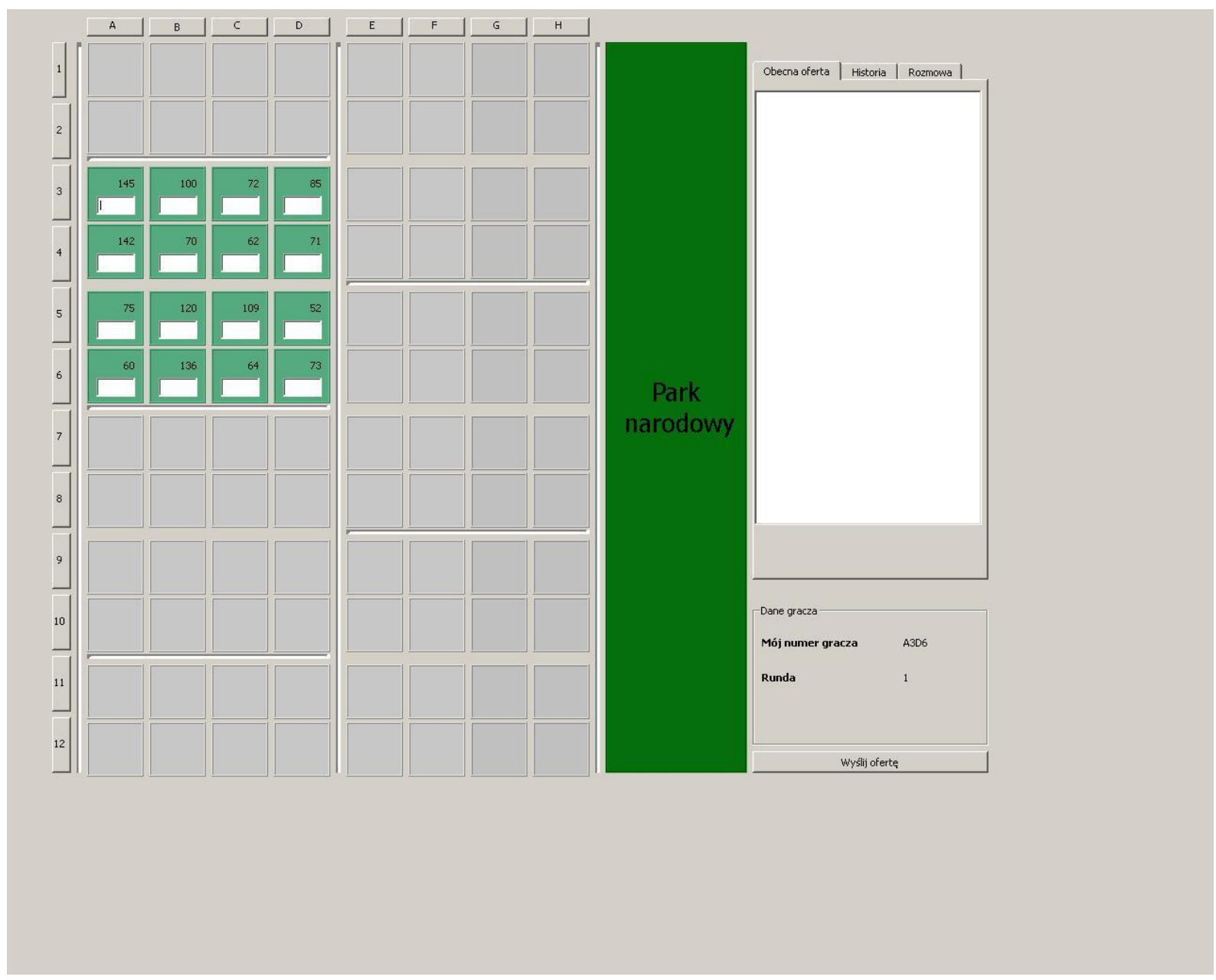

Figure A1. An exemplary screen shot at the beginning of the game. 


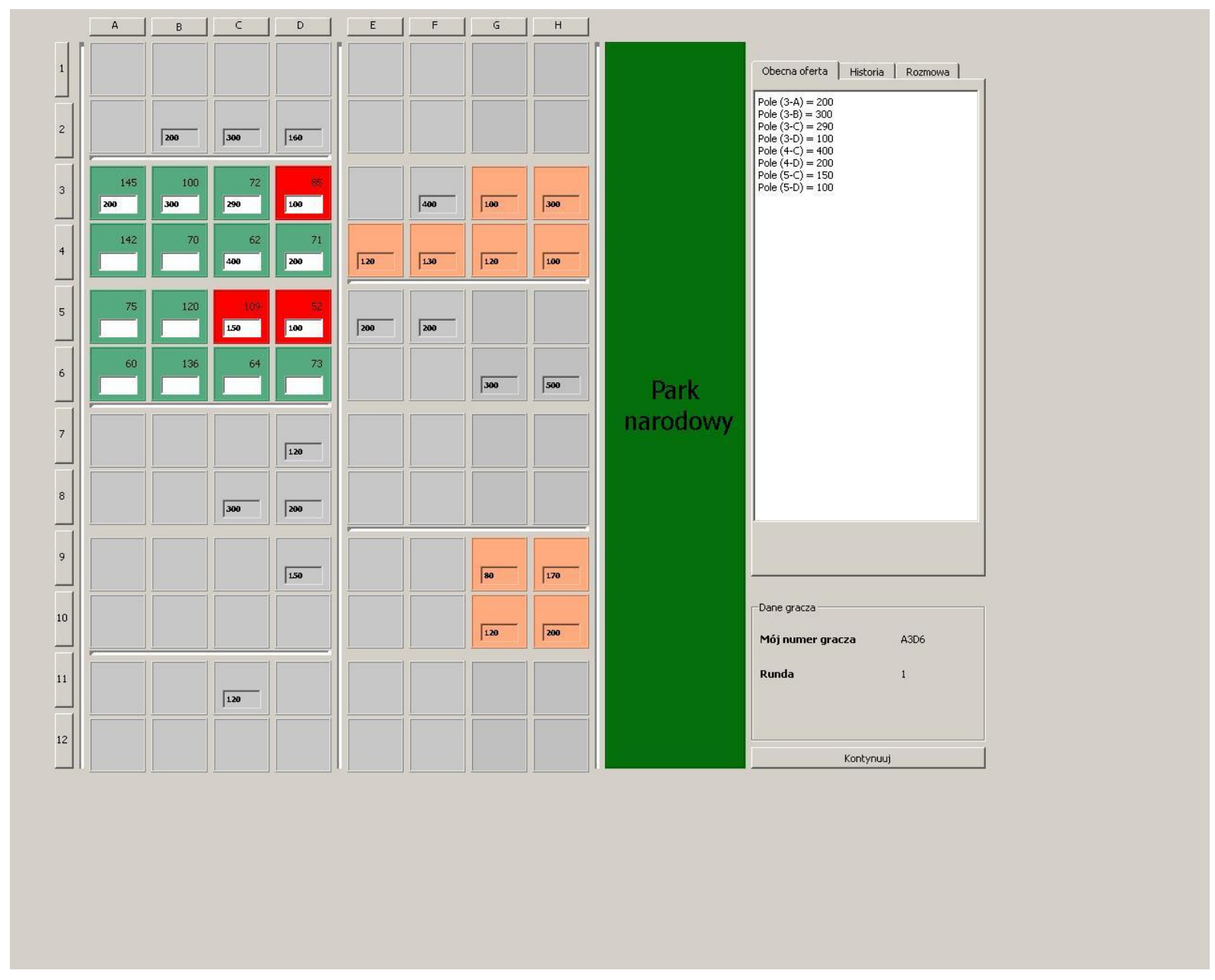

Figure A2. An exemplary screen shot of the situation after a round that was not the final round. 


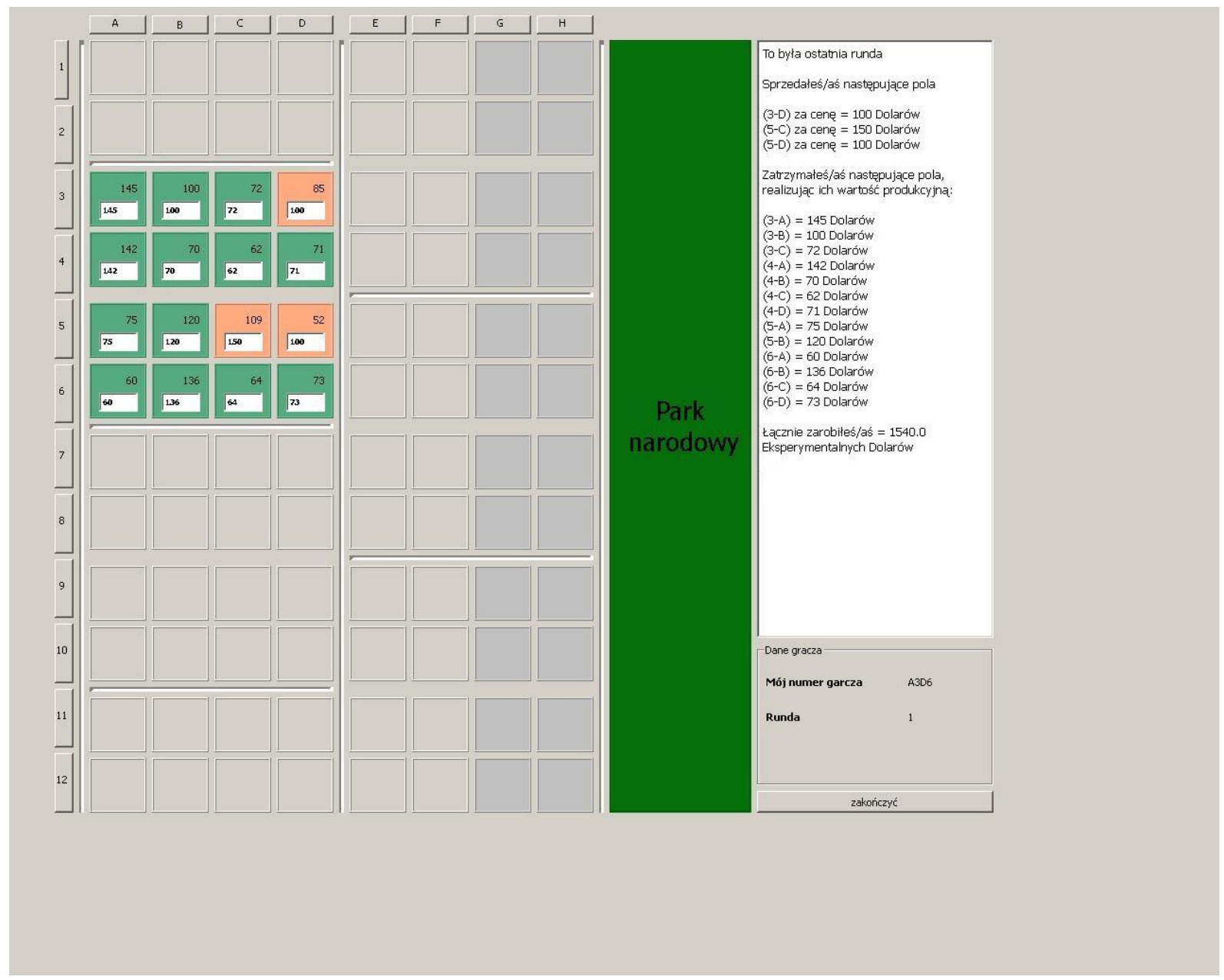

Figure A3. An exemplary screen shot of the situation after a round that turned out to be final. 


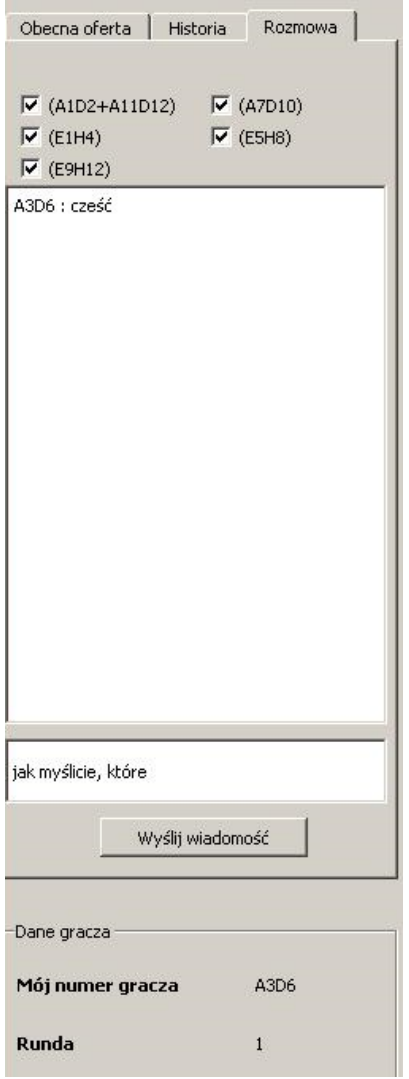

Figure A4. Chat screen. 


\section{Appendix. Experimental instructions for the "DPC" treatment.}

Thank you for your interest in our experiment! During the experiment you will be able to earn Experimental Dollars. The amount of money you earn will depend on your choices and the choices of other participants. At the end of the experiment Experimental Dollars you earn will be exchanged into Polish zloty.

Please turn off your cell phones and refrain from talking or communicating with other participants in any other way, with the exception of using the chat dialogue box, as described below. Participants disobeying this rule may be excluded from the experiment without receiving any payment. In case of any questions or doubts please alert the experimenter by raising your hand.

In this experiment you have been assigned to a GROUP of six.

Each member of the group is in possession of a forest PROPERTY consisting of 16 FIELDS. The PROPERTIES of players may be closer to of further away from the NATIONAL PARK. For example, the screen shot provided (Figure A1) shows the situation of a participant of the experiment, who possesses a PROPERTY not in immediate proximity to the PARK, consisting of fields: 3-A, 3-B, ..., 6-C, 6-D, (the FIELDS marked with color green).

The narrow white lines separate the PROPERTIES of each of the six members of the group. Fields marked 1-A, $\ldots, 1-D, 2-A, \ldots, 2-D$, and fields 11-A, ..., 11-D, 12-A, ..., 12-D (upper and lower left hand corner) comprise a single property, that is, are in possession of a single participant.

<Figure A1.>

Each FIELD has its own PRODUCTION VALUE, for example, 4-B has the PRODUCTION VALUE of 70. It is the value of that field to the owner (for example profits from selling timber). If by the end of the experiment the FIELD is still in possession of the owner, he or she will be granted 70 Experimental Dollars. 
The PRODUCTION VALUES of different FIELDS comprising your PROPERTY will vary. The rationale behind this is the varying density of the forest on various FIELDS, or different ages or species of the trees. The value of each FIELD will be constant during the whole experiment. Each participant knows the PRODUCTION VALUE of every FIELD in his or her possession, but does not know the values of FIELDS which belong to other participants.

An AUCTION will take place during the experiment, during which you will have the possibility to sell some or all of your FIELDS to the GOVERNMENT. The GOVERNMENT buys the FIELDS in order to protect the buffer zone of the NATIONAL PARK and to create migration corridors for animals from different dwellings. The GOVERNMENT is NOT represented by any participant in the experiment, its behavior had been pre-programmed by the experimenters. Participants are not allowed to buy or sell FIELDS from or to other participants (owners of other properties).

- The AUCTION consists of MULTIPLE ROUNDS

- Only the FINAL ROUND determines the earnings in Experimental Dollars, which in turn determine your earnings in zloty.

- The results of past ROUNDS inform you of the earnings you would have, if that round had been final one.

- However, we will not explicitly state which ROUND will be FINAL. This depends on the behavior of all of the participants in subsequent rounds. By bidding in any given round you acknowledge that it might turn out to be the FINAL ROUND and the results will be binding (that means that the FIELDS you put up for sale will be bought by the GOVERNMENT for the price you list).

\section{YOUR STEPS IN THE AUCTION:}

- In each ROUND you can put up for sale any number of the 16 FIELDS in your possession (you can choose not to offer any)

- For each FIELD you put up for sale you must name a price (a BID). The BIDS may vary for different FIELDS. 
- Enter the BID for each FIELD you want to put up for sale into the text box (or leave it blank if you do not wish to sell it in this round).

- Submit your BID.

At the end of a ROUND it might turn out that you have "sold" one, many, all or none of your FIELDS. The "sold" FIELDS will be marked RED. You will also find out what the BIDS of other participants were, and which of them were "accepted". The "accepted" bids will be marked ORANGE.

If the ROUND in question will not turn out to be the FINAL ROUND, the transactions are VOID. That means the results are not binding and do not have consequences either for you or for the other participants (that is why the terms "sold" and "accepted" in the previous paragraphs have been put in quotation marks).

If the current ROUND is followed by another you then repeat this procedure with all the 16 FIELDS originally in your possession, with the PRODUCTION VALUE of each field remaining unchanged (that is, the fact that you provisionally "sold" any specific FIELD in the previous ROUND has no effect in the current round-you still own it).

You can however change the BIDS and/or the FIELDS you wish to put up for sale in each ROUND.

Figure A2 shows the situation after a certain ROUND which did not turn out to be FINAL. Not all the BIDS of the selected participant have been "accepted", only those marked RED. For example, he or she succeeded in "selling" (BID of 100) FIELD 3-D, but he did not "sell" FIELD 3-C with the BID 290. The figure also shows the BIDS (but not the PRODUCTION VALUES) for FIELDS that belong to other participants. For example the owner of FIELDS from columns E-H and rows 1-4 "sold" 6 of his or her FIELDS, but failed to "sell" the FIELD 3-F for a price of 400. Naturally he or she also did not sell their remaining 9 FIELDS, none of which have been put up for sale. In the next ROUND each participant is allowed to raise or lower the BID for each FIELD, as well as change the combination of FIELDS he or she puts up for sale.

<Figure A2> 
If a given ROUND turns out to be FINAL and a certain BID gets accepted, the GOVERNMENT buys the FIELD from you at the price equal to the BID. Naturally you will not receive money for the PRODUCTION VALUE of the FIELDS you have sold.

Your earnings in the experiment will be calculated according to the formula:

SUm of BIDS for sold FIELDS + sUm of PRODUCTION VALUES of FIELDS not sold = earnings in Experimental Dollars

For every Experimental Dollar you earn you will be granted .015 zloty. For example, should your earn 2000 Experimental Dollars, you will receive 30 zloty.

CAUTION: EAch ROUND could be the FINAL ROUND!

Figure A3. shows the situation after a ROUND that turned out to be FINAL.

<Figure A3>

The results are discussed for the selected participant only. Carefully read the text in the column to the right of the national park.

HOW DOES THE GOVERNMENT DECIDE WHICH FIELDS TO BUY?

The pre-programmed GOVERNMENT has the budget of $\mathbf{5 0 0 0}$ Experimental Dollars to buy FIELDS from the participants. It will try to spend that amount (or slightly less) buying the FIELDS offered by the participants in a way that will maximize the joint ENVIRONMENTAL VALUE (the benefit for the environment). The optimal combination is found by a special algorithm. After buying the FIELDS the GOVERNMENT will not exploit the terrain-it will neither extract timber nor disturb the ecological processes in that field. 


\section{The ENVIRONMENTAL VALUES vary between FIELDS.}

- FIELDS that lie in the buffer zone of the NATIONAL PARK (that is, in the columns adjacent to the PARK, marked with darker colors) are the most valuable.

- Buying FIELDS that form a horizontal line on the board offers a higher ENVIRONMENTAL VALUE than field that do not form a line. They are the corridors that will allow the animals to migrate between the NATIONAL PARK and other dwellings.

The exact formula that is used by the GOVERNMENT to calculate the aggregated value of the ENVIRONMENTAL VALUE of the FIELDS is as follows:

For each FIELD bought in columns A-F: 1 For each FIELD bought in columns $G$ and H: 2

Additionally, in case of acquiring a pair of FIELDS form the same row adjacent to each other (that is FIELDS that share a vertical border, creating a horizontal connection), regardless of the columns they are in, the ENVIRONMENTAL VALUE bonus equals 1.

For example, if the GOVERNMENT buys fields 6-D, 6-E, 7-E, 7-F and 7-G the total ENVIRONMENTAL VALUE equals:

$1[$ for 6-D] $+1[6-E]+1[7-E]+1[7-F]+2[7-G$ is in the buffer zone] +1 [bonus for adjacent 6-D and 6-E] +1 [bonus for adjacent 7-E and 7-F] 1 [bonus for adjacent 7-F and 7-G] $=9$

Take note that:

- No additional ENVIRONMENTAL VALUE is added for FIELDS that share a horizontal side thus creating a vertical connection (here: 6-E and 7-E)

- The ENVIRONMENTAL VALUE bonus connected with creating a horizontal connection does not take into account whether the FIELDS belonged to one or two participants. 
What are the implications of such behavior of the government for you:?

- If your BID is too high you will not sell said FIELD. You will be left only with its PRODUCTION VALUE.

- The question whether a certain BID is "too high" depends mostly on the behavior of other participants - in general you will not be able to sell FIELDS that are relatively more expensive than FIELDS offered by others.

- Additionally, the maximum BID for said FIELD that the GOVERNMENT will be willing to accept will be considerably higher for FIELDS more attractive to the GOVERNMENT in terms of environmental benefits- that is those located in columns $G$ and $H$ and those that together create a horizontal corridors with other FIELDS offered either by you or by other participant.

\section{CONVERSATION BETWEEN PARTICIPANTS}

Perhaps you have noticed the tab "Chat" [Polish: Rozmowa] on Figures A1 and A2. Participants belonging to the same GROUP of 6 have the possibility to communicate with each other via this tool. The Figure A4 on the right shows how to use it.

< Figure A4 - on the right side of this paragraph>

The screen shot presents the point of view of a participant who has FIELDS in columns A-D and rows 3-6 (A3D6). In the upper part of the panel he or she can choose which of the other 5 participant he or she wishes to contact. Type each message into the text box immediately above the "Send message" button. In the captured moment the participant began to type a new message "What do you think, which" to all of the other participants. All sent and received messages will appear in the bigger text panel above. As you can see, the chosen participant has previously 
sent a message "Hello" [Polish czesc]. You will be able to send and receive messages in every round of the auction. Naturally you do not have to use this tool.

You can use this tool to ask questions, make proposals or promises, reveal your plans, comment on the actions of others, coordinate strategies etc.

ATTENTION! You can send any message, as long as you abide by the following rules:

- You are not allowed to use words or expressions that are considered vulgar or aggressive or to offend other participants.

- You are not allowed to reveal your true identity (first or last name, etc.) or physical location in the lab, or to encourage anyone else to do so.

- You are not allowed to make promises or threats that would extend beyond the experiment (for example promise to share your winnings or threat to withhold social contact) or to encourage anyone else to do so.

The experimenter has the possibility of inspecting the content of sent messages both during the duration of the experiment and after it is finished. Blatant disregard for the rules listed above will result in your exclusion from the experiment without earnings. If you believe that another participant has broken the rules of chat please raise your hand and wait for the experimenter.

Raise your hand in case of any questions. If not, please press the button on the screen to begin. 